Case Study

\title{
Performance assessment of milk processing system using Petri nets
}

\author{
Narendra Kumar ${ }^{1}$ (D) P. C. Tewari ${ }^{1} \cdot$ Anish Sachdeva $^{2}$
}

Received: 23 December 2019 / Accepted: 29 July 2020 / Published online: 10 August 2020

(c) Springer Nature Switzerland AG 2020

\begin{abstract}
The study presents the quantitative effect of the recorded failure and repair data on the performance of a liquid milk processing plant in terms of its availability and reduced capacity. Process modeling and behavioral analysis of the system has been carried out by dividing the system into four subsystems placed in series using Petri Nets approach. A licensed software package (named Petri module of GRIF) has been used for model formalism and its simulation. The results of this study are expected to be useful to the proprietors of the milk processing plant as well as for practitioners from other fields such as multiprocessor electronic systems, telecommunication systems and production systems among others who want to analyze, understand and predict the behavior of various types of equipments. Reliability, Availability, and Maintainability modeling tools described here can be of helpful to them in planning selective maintenance strategies for their systems.
\end{abstract}

Keywords Availability analysis · Maintenance $\cdot$ Modelling tools $\cdot$ Profitability $\cdot$ Petri nets

\section{Introduction}

In the present business scenario achieving and maintaining specific level of operational availability of sophisticated and complex systems is highly competitive and challenging. It requires substantial capital investment, and any shortcoming may lead to consequences that result into penalty in terms of safety, revenue as well as reputation etc. The survival of such systems depends very much upon the design and development of an appropriate efficient system that has high payback ratio. In view of this every plant manager wants to have a system that operates smooth and failure-free under the specified operative conditions that can help him in achieving the set goal of production volume and quality.

In the present study, detailed investigation of the performance realistic industrial system of a liquid milk processing plant that consists of several dependent subsystems with non-constant failure rates has been considered.
We have used the Generalized Stochastic Petri Nets (GSPN) approach to model and evaluate the system behavior in terms of its availability and reduced capacity mode. Subsequent effect of availability on the profitability of the plant under varying failure and repair parameters of various subsystems has also been analysed and a Decision support System (DSS) has been proposed which can be useful for making strategies like requirement of spare parts, maintenance priorities and human resource required etc. The study is intended to emphasize the use of RAM tools in various stages of the plant life cycle. The following subsections present the detailed classification of modeling tools.

\subsection{Modeling tools}

In the last few decades, a large amount of research has dealt with the realistic industrial problems and proposing means for developing efficient models of the systems in hand using appropriate modeling tools. To begin with,

\footnotetext{
$\triangle$ Narendra Kumar, narendra_6160054@nitkkr.ac.in; P.C. Tewari, pctewari1@rediffmail.com; Anish Sachdeva, asachdeva@nitj.ac.in | 1 Department of Mechanical Engineering, National Institute of Technology, Kurukshetra 136119, India. ${ }^{2}$ Department of Industrial and Production Engineering, Dr. B.R. Ambedkar National Institute of Technology, Jalandhar 144011, India.
} 
these tools were being applied to simple systems. However the systems now being investigated are technologically sophisticated. In this study, we first describe in brief these modeling tools which are based on quantitative and qualitative methods as well as softwares which are categorized into state space and non-state space modeling tools.

Goel [1] described certain factors that are helpful in selecting an appropriate modeling tool for formalizing the system behavior. These are:

- Measures of interest such as steady-state or timedependent, reliability, and availability.

- Structural complexity and size of the system

- Techniques available to solve the model

- Quality of collected data

The classification of the performance modeling tools is presented in Fig. 1.

A detailed description of various performance modeling tools that can describe and measure the behavior of the system in terms of reliability and availability is presented in Narahari and Viswanadham [2]. The four methods that are being widely used are Reliability Block Diagram (RBD) tool, the Fault Tree (FT) tool under no state-space models and Petri Nets and Markov tools under state-space models. These are shown diagrammatically in Fig. 1 . In the case of the RBD technique, the blocks represent system elements configured in series and parallel subsystems. Further parallel and series configuration are reduced to equivalent units until the whole system reduces to a single unit. It is a useful and straightforward procedure for systems that consist of series and parallel subsystems. Simplicity in its understanding and applying is the primary advantage of this approach. However this method is not suitable for components and systems working in degraded states. In such cases, Markov method is preferable as it can usually handle more cases than other techniques. It can not only be used in cases where the components are independent but also for systems involving dependent failure and repair modes. Gupta and Tewari [3], Okafor et al. [4], Kumar et al. [5], Dahiya et al. [6] and recently Gupta et al. [7] used a Markov birth-death process technique to formulate the mathematical performance model and evaluate system availability measures. However, Markov models are too complex and challenging to analyze for systems with a more significant number of states and subsystems. Petri Nets modeling is comparatively simple. It also eliminates the limitations of the Markov method. Petri Nets modeling and its extensions are highlighted in the next subsection.

\subsection{Petri nets}

A classical Petri Nets (PN) model was proposed by C. A. Petri in his doctoral thesis in 1962. Since then, many extensions to this technique have been developed to further increase its modeling power and application to analyze a wide range of industrial and non-industrial practices. Basically Petri net is a bipartite directed graph with strong mathematical representation supporting concurrency, synchronization and randomness consisting of places, transitions, arcs and tokens represented by circles, rectangular bars, arrows and big circular dots centered in places respectively [2]. An illustrative PN model is shown in Fig. 2. Tokens are stored in places and move from one place to another along arcs through transitions. A marking is an assignment of token to the place and these may change during the execution of a Petri net. If the transition firing times are stochastically timed, the Petri net is called a Stochastic Petri net (SPN). If the transition firing is distributed exponentially, it is possible to make a statistical approximation of the same availabilities as those of homogeneous continuous Markov chains models. A brief review of some extended PN models is as under.

Marson et al. [8] proposed the Generalized Stochastic Petri Net (GSPN). This is an extension of SPN that allows the transitions of the underlying $\mathrm{PN}$ to belong to two different classes, namely immediate and timed transitions. Immediate transitions are drawn as black bars that fire in zero

Fig. 1 Classification of modeling techniques

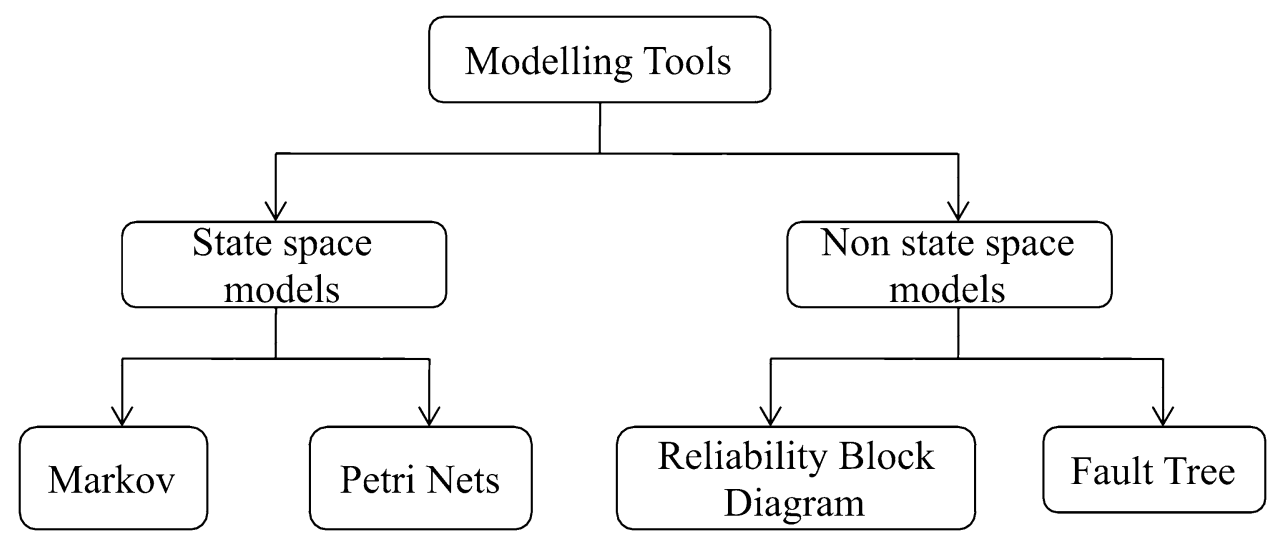


Fig. 2 An illustrative Petri net model
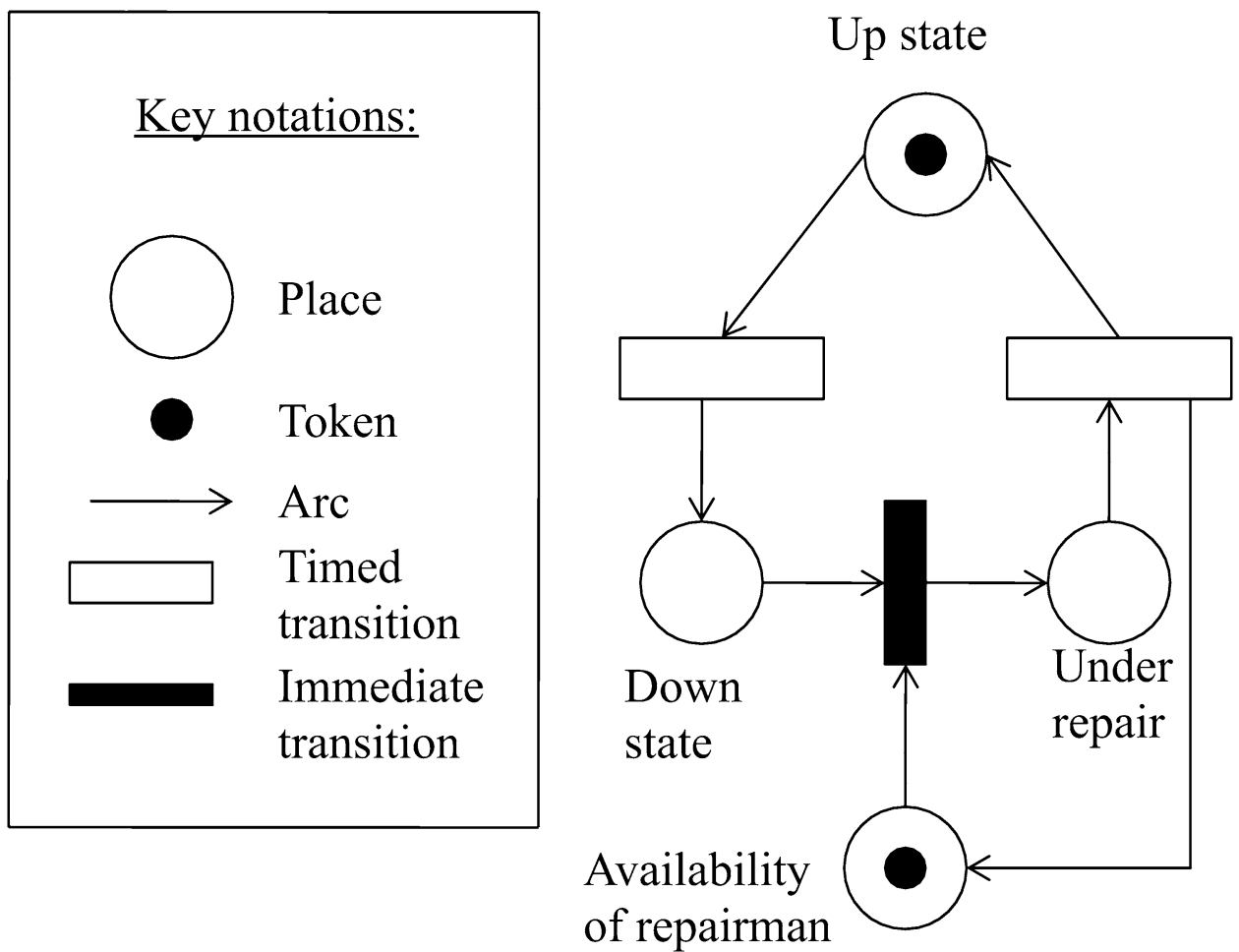

time once enabled whereas timed transitions are denoted by unfilled rectangular boxes (shown in Fig. 2). These are assigned firing rates just as in SPN. Singh and Garg [9], Sachdeva et al. [10, 11], Thangamani [12], Kumar et al. [13], Tavana [14], Ferreira et al. [15] applied GSPN for modeling and availability analysis of different industrial systems.

To reduce the limitations of GSPN Dugan et al. [16] proposed at Duke university in 1984 an extended class of SPN called Extended Stochastic Petri Net (ESPN). It includes inhibitor arcs, counter arcs and probabilistic arcs. In this net, it is possible to use customized firing time distributions. It is best suited for the system having assembly lines. A further extension of GSPN is Deterministic Stochastic Petri Net (DSPN) which allows defining immediate, exponentially distributed, and deterministically timed transitions. The graphical representation of DSPN is same as GSPN except for some specified firing conditions. Deterministic transitions are represented by dark rectangular boxes [2].

Trivedi et al. [17] introduced a new class of SPN, which were named Concurrent Stochastic Petri Net (CSPN). These nets allow simultaneous enabling of several customized timed transitions.

Colored Petri Net (CPN) is a high level PN which was proposed by Kurt Jensen [18]. It is based on the concept of colored tokens to distinguish various elements. These multi colored tokens identifying a particular type of subsystem use same place and transitions for firing in the normal way, except for a specified condition. CPN formalism has been applied by Feldmann and Colombo [19] and Haisheng Li et al. [20] for modeling and analysis of flexible production systems. Extensive research has been carried out in recent years by Donatelli and her associates in this field. Recently Timed Automata has been used for the verification of Stochastic Models (Donatelli et al. [21]). Petri net has been well surveyed by different researchers as well as in some text books from time to time. Desrochers and Al-Jar [22], Zhu [23] have presented surveys on PN. Two springer Verlag volumes edited by Brauer et al. [24, 25] are state of art survey papers on classical PN and SPN by leading researchers in this field. Kurkovsky and Loganantharaj [26], Aggarwal et al. [27], Dekker and Groendijk [28], Dhillon and Yang [29], Kucharik and Balogh [30] and Molloy [31] have also made significant contributions in this field.

In the present study, a milk processing system has been analysed using GSPN approach.

The rest of the paper is organized as under: in Sect. 2, the system description is mentioned, performance model is developed in Sect. 3, in Sect. 4, performance analysis and illustrations of effect of failure and repair parameters is described, in Sect. 5, discussion of results were presented and finally, the conclusions with DSS is drawn in Sect. 6. 


\section{System description}

In this study, the working of a milk processing and filling line is analyzed. The system involves processing of raw milk that plant receives from farmers into marketable milk, conforming to the regulations of food safety standards and guidelines being followed in the country's policy on food safety. The raw milk received in the plant goes through filtration, testing, chilling, standardization, homogenization, pasteurization, and packing of liquid milk and milk products of different kinds. The flow diagram of 100,000 L per day milk processing plant is shown in Fig. 3. As the performance of its subsystems affects the availability and quality of the final product, every stage of the process has to be analyzed carefully. The quality of the final product is also dependent on hygiene and compliance of specified standards to guarantees the quality of the final packed milk.

Some essential functional installations which work as its subsystems are:

I. Cream separator Cream separator separates the oil molecules in the milk. In order to make it free of harmful bacteria, unwanted solid particles need to be efficiently separated. It works on the principle of centrifugal force. A rotating drum at about $7000 \mathrm{rpm}$ creates enough centrifugal force that is needed for the separation of solid particles and liquid mixture. Whereas high-density substances get collected in the drum's interior wall, low-density materials accumulate in the central region of the drum. Skim milk and fat globules leave the separator from a place that is near the rotating axis at the
Fig. 3 Flow diagram of milk processing and filling line

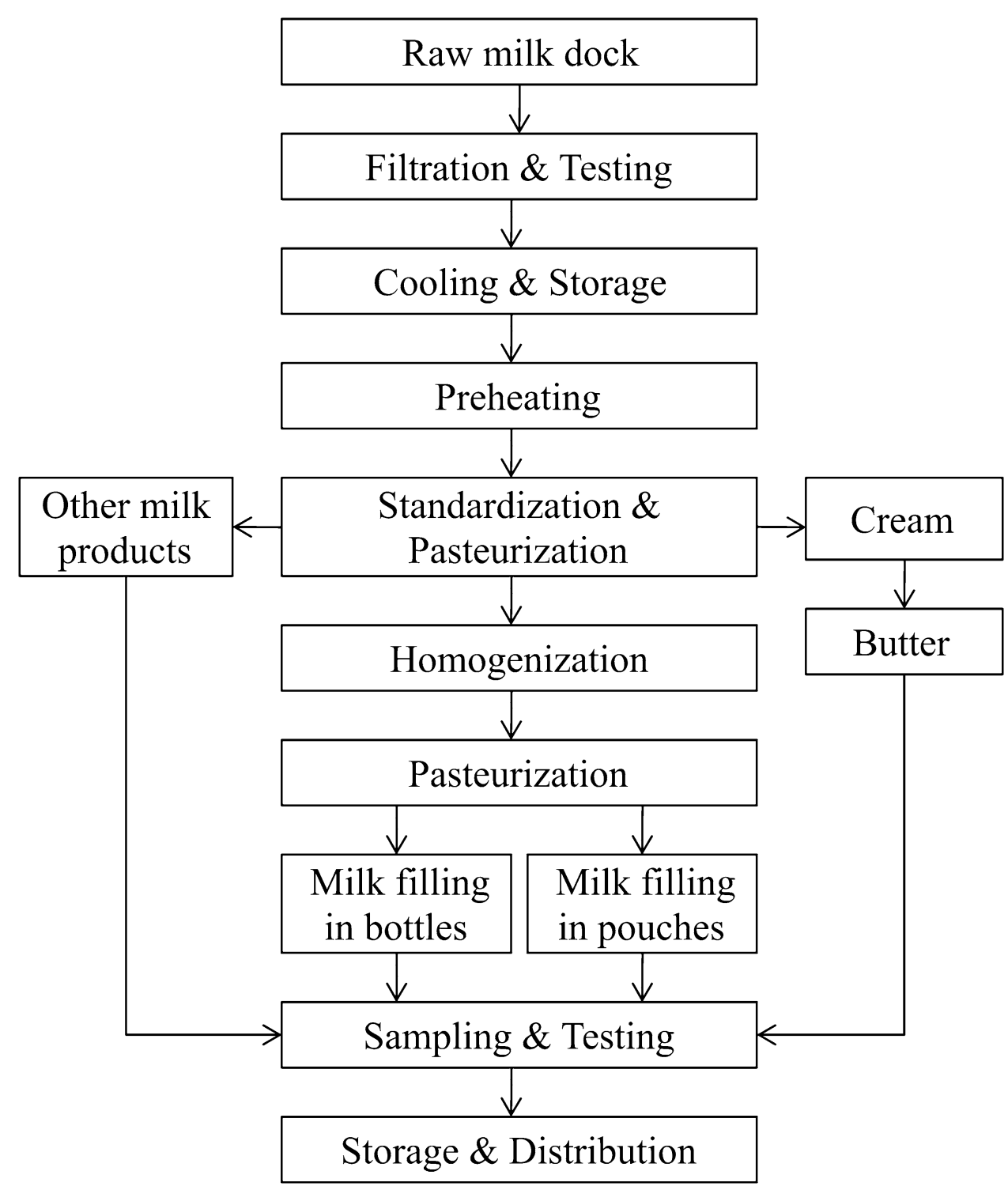


exit area that is at the top of the drum. To prevent any mixing of cream and skim milk, these are collected in different vessels. The subsystem consists of three components in series. These are motor, bearings, and high-speed gearbox.

II. Homogenizer Homogenizer is used to split up the fat globules to below 2-micron sizes. This occurs in a steel valve assembly placed between two pieces of steel, as shown in Fig. 4. In the first stage most of the fat globule reduction takes place. Reduced-fat globules tend to clump or cluster. The product is next passed through a second stage valve, which is similar to the first stage valve. This valve permits the separation of these clusters into individual fat globules.

III. Pasteurizer The plant under study uses a HighTemperature Short Time (HTST) pasteurization technique for pasteurization. It makes use of hot water and metal plates to raise milk temperature to a critical control temperature of $72^{\circ} \mathrm{C}$ for at least $16 \mathrm{~s}$. This is followed by rapid cooling. Pasteurization is done for the elimination of bacteria and other pathogenic organisms and of at the same time, maintaining and preserving its nutritional values. It has a holding tube, regenerator, timing pump, flow diversion device, and vacuum breaker as its major components. These work in series. It is used to destroy pathogenic organisms and other undesirable organisms. It also inactivates the present enzymes and removes its volatile flavors.

IV. Filler This subsystem comprises of a pouch as well as bottle filling machines. Liquid milk product is filled in sterilized pouches having film thickness ranging from 46 to $50 \mu \mathrm{m}$. It involves the use of a non-contact nozzle located just above the neck of the pouch to prevent milk spilling. Once the specified capacity of milk is received valve automatically shuts off. Next, the pouch is sealed from top and bottom using the heating element provided in the machine. The conveyor transports the sealed packets. This subsystem has a printed circuit board and a pneumatic cylinder arranged in series. This is, in fact a fill, flow and automatic seal machine.

In the Bottle Filling Machine, the product is filled in rinsed and sterilized bottles. This involves the use of noncontact valves which are located just above the neck of the bottle. However, these are not in contact with the bottle. This prevents the milk from spilling on the bottleneck ring as it can cause bacteria and mold growth in a short time once the container is closed. This spoils the milk. The milk is filled directly volumetrically into the bottle. The valves work at constant pressure. This prevents foaming and spillage of milk. Once milk of specified capacity is filled the valve automatically shuts off. The bottle is next transferred to the capping machine.

\section{Performance modeling}

In order to analyze the performance of such a system, its modeling has been done using GSPN. Mean time between failure (MTBF) and Mean time to repair (MTTR) data for the study were obtained from the maintenance logbook of the plant in consultation with the supervisors of a reputed milk plant in Haryana (India). MTBF represents the mean time between two successive failures and MTTR the mean time to restore it. Failure and repair rates are the reciprocals of
Fig. 4 Homogenization mechanism

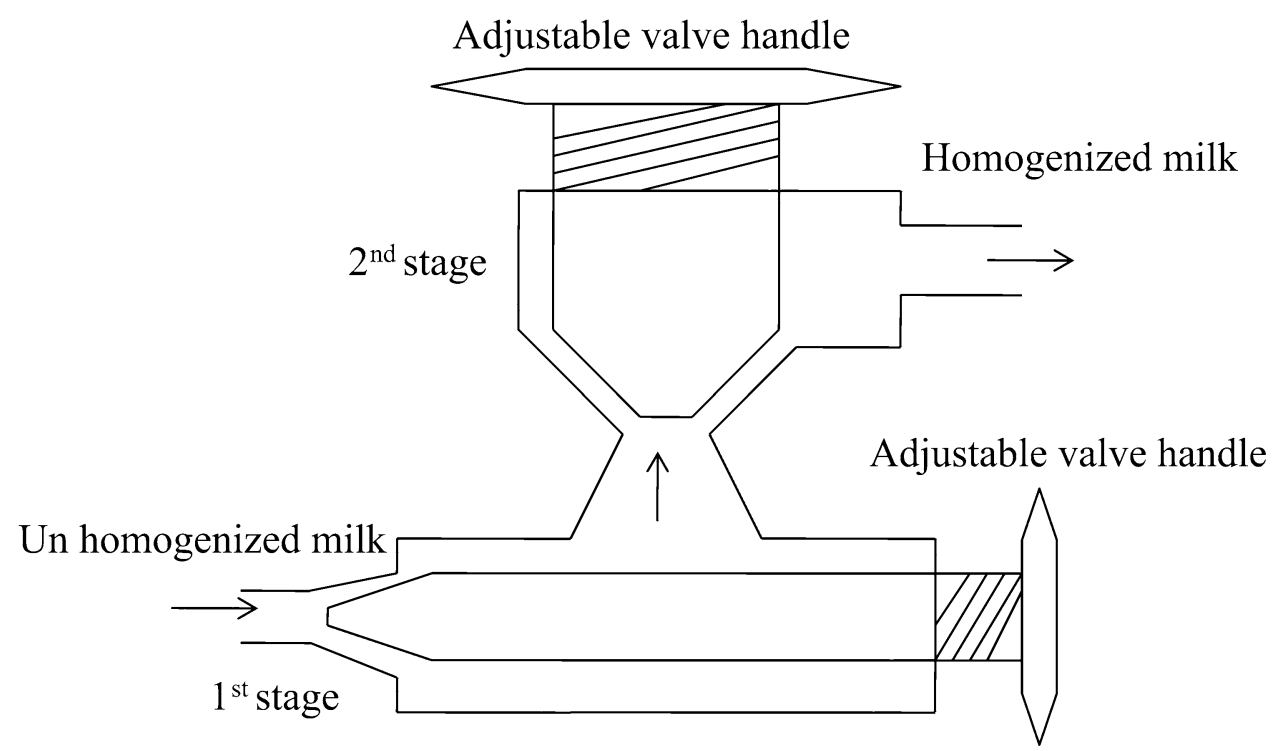

SN Applied Sciences A SPRINGER NATURE journat 
MTBF and MTTR respectively. Time-dependent failure data is modeled using Weibull distribution, and repair data are modeled using Exponential distribution. This is presented in Table 1. The parametric values shape and scale parameters of Weibull distribution were obtained using the least square method of curve fitting. The developed Petri Nets model with a single repair facility is presented in Fig. 5 . Computer programming and simulation to analyze the performance and behavioral analysis of the system have been carried out using a licensed package of GRIF software of the Petri module.

The places and transitions used in this model have the following meanings:

\section{Places}

- Sys_up $\left(P_{16}\right)$ represents the milk processing system in the upstate.

- Sys_dn $\left(P_{17}\right)$ represents the milk processing system in the downstate.

- Sysfull_cap $\left(P_{14}\right)$ represents the milk processing where it is working in full capacity.

- Sysred_cap $\left(P_{15}\right)$ represents milk processing in a reduced capacity.

- Rep_avail $\left(\mathrm{P}_{13}\right)$ represents the availability of the repair facility.
Table 1 Failure and repair data of liquid milk processing system

\begin{tabular}{|c|c|c|c|c|}
\hline \multirow[t]{2}{*}{ Name of the subsystem } & \multicolumn{3}{|c|}{ Weibull parameters of failure data } & \multirow{2}{*}{$\begin{array}{l}\text { Exponentially distrib- } \\
\text { uted repair data } \\
\text { Repair rate }\left(\mu_{\mathrm{i}}\right) \text { per hour }\end{array}$} \\
\hline & $\begin{array}{l}\text { Shape } \\
\text { parameter( } \beta)\end{array}$ & $\begin{array}{l}\text { Scale } \\
\text { Parameter }(\theta)\end{array}$ & $\begin{array}{l}\text { Mean time between } \\
\text { failure }\left(\mathrm{MTBF}_{\mathrm{i}}\right) \text { in } \\
\text { hour }\end{array}$ & \\
\hline Cream separator (I) & 2.10 & 330 & 307.0 & $3.0 \times 10^{-1}$ \\
\hline Homogenizer (II) & 1.21 & 443 & 410.0 & $1.2 \times 10^{-1}$ \\
\hline Pasteurizer (III) & 1.13 & 452 & 408.0 & $1.3 \times 10^{-1}$ \\
\hline Filler (IV) & 1.78 & 1171 & 1131.0 & $9.0 \times 10^{-3}$ \\
\hline
\end{tabular}
Exponentially distributed repair data
$1.3 \times 10^{-1}$

\section{PASTEURIZER \\ PASTEURIZER
Past_up}

HOMOGENIZER

Sep_fail

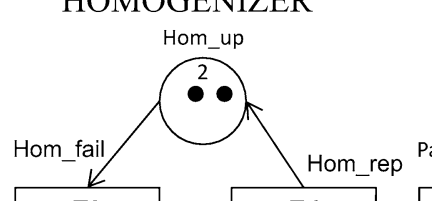

FILLER

Past_fail
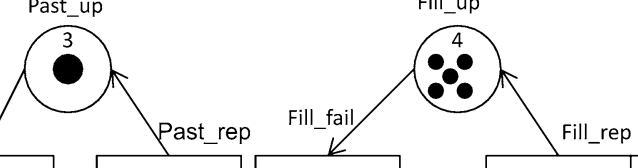
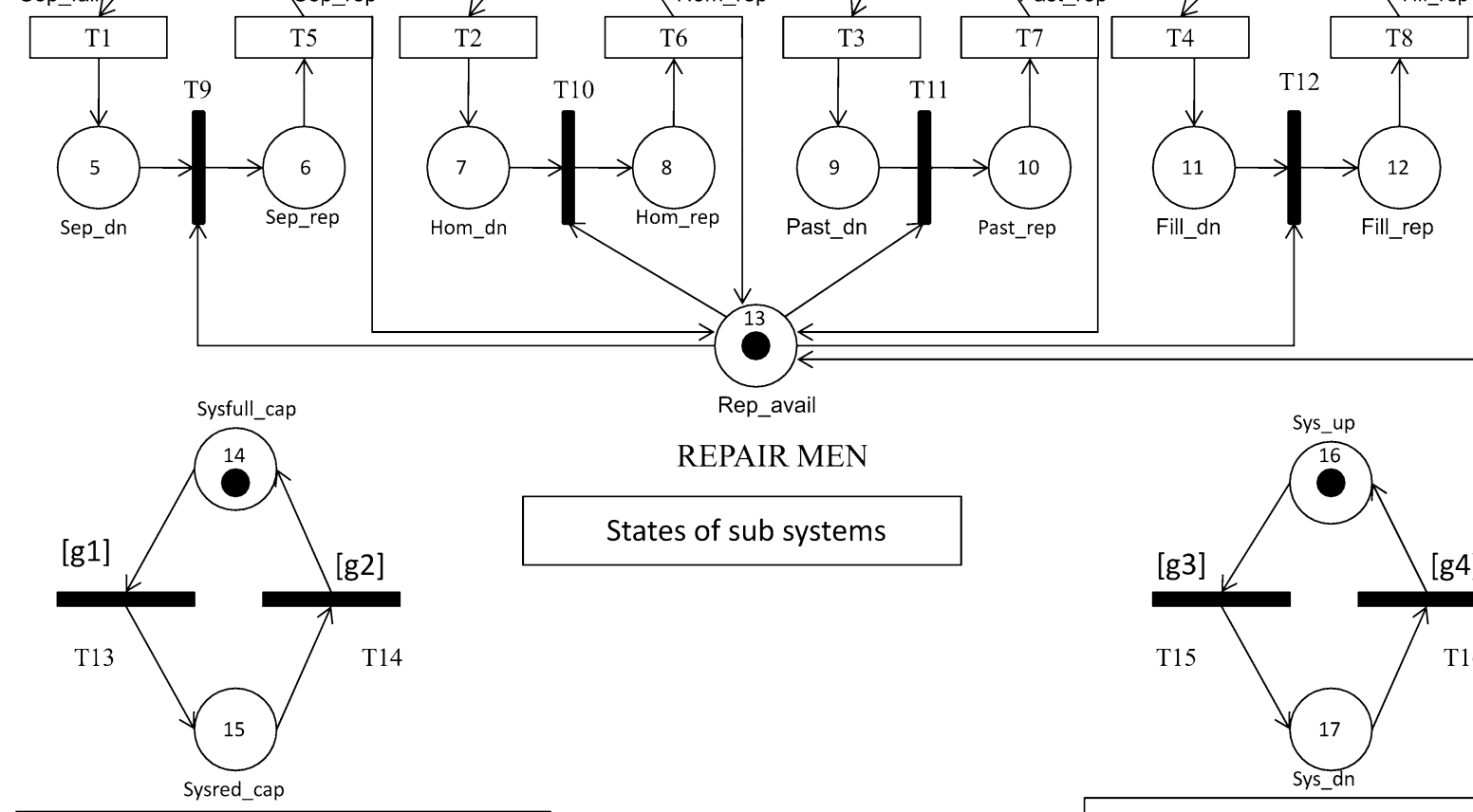

Rep_avail

Past_dn

Past_rep

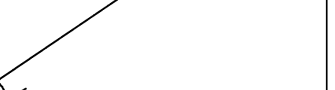

REPAIR MEN

States of sub systems

System availability in reduced capacity

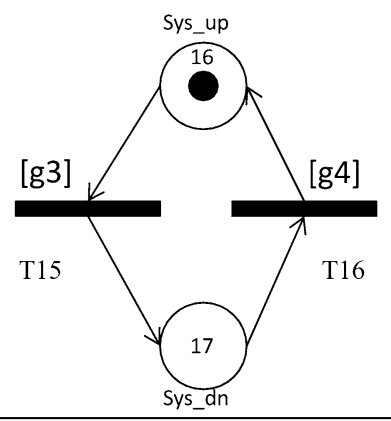

System availability

Fig. 5 Petri Nets model of the system 
- Sep_up $\left(P_{1}\right)$, Hom_up $\left(P_{2}\right)$, Past_up $\left(P_{3}\right)$, and Fill_up $\left(\mathrm{P}_{4}\right)$ represent the working states of Separator, Homogenizer, Pasteurizer and Filler, respectively.

- Sep_dn $\left(P_{5}\right)$, Hom_dn $\left(P_{7}\right)$, Past_dn $\left(P_{9}\right)$, and Fill_dn $\left(P_{11}\right)$ represent the down states of Separator, Homogenizer, Pasteurizer and Filler, respectively.

- Sep_rep $\left(P_{6}\right)$, Hom_rep $\left(P_{8}\right)$, Past_rep $\left(P_{10}\right)$, and Fill_rep $\left(P_{12}\right)$ represent the repair states of Separator, homogenizer, Pasteurizer and Filler, respectively.

\section{Timed transitions}

- Sep_fail (T1), Hom_fail(T2), Past_fail(T3), and Fill_ fail(T4) are timed transitions. These are associated with mean time between failures $\left(\mathrm{MTBF}_{1}, \mathrm{MTBF}_{2}, \mathrm{MTBF}_{3}\right.$, and $\mathrm{MTBF}_{4}$ ) of Separator, Homogenizer, Pasteurizer and Filler respectively.

- Sep_rep (T5), Hom_rep(T6), Past_rep (T7) and Fill_ rep(T8) transitions are also timed. These are associated with repair rates $\left(\mu_{1}, \mu_{2}, \mu_{3}\right.$, and $\left.\mu_{4}\right)$ of Separator, Homogenizer, Pasteurizer and Filler respectively.

Immediate transitions

- Seprep_avail (T9), Homrep_avail (T10), Pastrep_avail (T11), and Fillrep_avail (T12) are immediate transitions. These are associated with availability of repair facilities for Separator, Homogenizer, Pasteurizer and Filler respectively.

- Sys_red (T13), Sys_full (T14), Sys_fail (T15) and Sys_up (T16) are also immediate transitions. These are associated with the system that works with reduced capacity, full capacity, failed state and up state and respectively.

\subsection{Programming for Guard functions}

The PN model shown in Fig. 5 is based on computer program written for guard functions associated with various transitions. These are:

- $[\mathrm{g} 1]=\left(\left(\# \mathrm{P}_{7}>0\right.\right.$ or $\left.\# \mathrm{P}_{8}>0\right)$ or $\left(\# \mathrm{P}_{2}>0\right)$ and $\left(\# \mathrm{P}_{2}<2\right)$ or $\left(\# P_{11}>0\right.$ or $\left.\# P_{12}>0\right)$ and $\left(\# P_{4}>0\right)$ and $\left.\left(\# P_{4}<5\right)\right)$ disables the transition Sys_red.

- $[g 2]=\left(\# P_{2}>1\right.$ and $\left.\# P_{4}>4\right)$ enables the transition Sys_full.

- $[\mathrm{g} 3]=\left(\left(\# \mathrm{P}_{5}>0\right.\right.$ or $\left.\# \mathrm{P}_{6}>0\right)$ or $\left(\# \mathrm{P}_{7}>0\right.$ and $\left.\# \mathrm{P}_{8}>0\right)$ or $\left(\# P_{9}>0\right.$ or $\left.\# P_{10}>0\right)$ or $\left(\# P_{11}>3\right.$ and $\left.\left.\# P_{12}>0\right)\right)$ disables the transition Sys_fail.

- $[\mathrm{g} 4]=\left(\# \mathrm{P}_{1}\right.$ and $\# \mathrm{P}_{2}>0$ and $\# \mathrm{P}_{3}>0$ and $\left.\# \mathrm{P}_{4}>0\right)$ enables the transition Sys_up.

Following assumptions have been made for modeling and analysis of the system:
- Exponential distribution is used to represent repair rate and Weibull distribution is used to represent failure rate.

- Failure and repair rates are statistically independent.

- The repaired unit is as good as a new one.

- The nature and capacity of the standby units are the same as of active units.

- There is negligible switchover time from active to standby units and vice versa.

- There is no delay in the start of repair except for the unavailability of repairmen.

- Repair priority is first-come, first-served basis.

- The system can be available in the reduced capacity mode also.

\section{Performance analysis}

The performance of the system has been analyzed in terms of the availability of the system using the Petri Nets technique. The modeling and simulation was done using a licensed software package named GRIF-predicates of the Petri module, using various parameters and their suitable predefined values. In this study where as the failure pattern is considered to follow Weibull distribution, repair time is assumed to follow exponential distribution. The parametric values of shape and scale parameters of Weibull distribution were obtained using least square method of curve fitting. The simulation run obtained the results for $10,000 \mathrm{~h}$ and for a large number of replications ranging from 10 to 21,000 by using the above mentioned software. The programming was done considering various parameters and their suitable predefined values. The performance analysis was carried out by changing the failure times MTBF and repair rates ( $\mu$ ) of each subsystem within the permissible range and keeping other subsystem parameters unchanged. Obtained results are presented in Tables 2, 3, 4 and 5 as array matrix. The maximum availability of the system was found to be $96.45 \%$, with a $95 \%$ confidence limit. Effect of availability on the profitability of the plant under varying failure and repair parameters of various subsystems has also been analysed and a Decision support System (DSS) proposed which can be useful for making strategies like requirement of spare parts, maintenance priorities and human resource requirements etc.

Figure 6a and Table 2a show that variation in failure and repair rates of the separator have a significant effect on the availability of the system. Decreasing MTBF of the separator from 387 to 227 (which increases the failure rate) and decrease in repair rate of the same from 0.40 to 0.20 reduces the system availability by as much as $4.30 \%$. However, the same variations in failure and repair rates of the separator have a negligible impact on the system's 
Table 2 Effect of failure and repair parameters of cream separator on the availability of the system; Effect of failure and repair parameters of cream separator in reduced capacity

\begin{tabular}{|c|c|c|c|c|c|c|}
\hline \multirow[t]{2}{*}{$\mathrm{MTBF}_{1}$} & \multicolumn{6}{|l|}{$\mu_{1}$} \\
\hline & 0.20 & 0.25 & 0.30 & 0.35 & 0.40 & Constant parameters \\
\hline \multicolumn{7}{|l|}{ (a) } \\
\hline 387.0 & 0.9381 & 0.9445 & 0.9506 & 0.9585 & 0.9628 & \multirow{5}{*}{$\begin{array}{l}(\mathrm{MTBF})_{2}=410, \mu_{2}=0.12 \\
(\mathrm{MTBF})_{3}=408, \mu_{3}=0.160 \\
(\mathrm{MTBF})_{4}=1131, \mu_{4}=0.009\end{array}$} \\
\hline 347.0 & 0.9344 & 0.9425 & 0.9500 & 0.9572 & 0.9619 & \\
\hline 307.0 & 0.9328 & 0.9347 & 0.9473 & 0.9563 & 0.9604 & \\
\hline 267.0 & 0.9296 & 0.9328 & 0.9435 & 0.9521 & 0.9582 & \\
\hline 227.0 & 0.9198 & 0.9284 & 0.9407 & 0.9493 & 0.9516 & \\
\hline \multicolumn{7}{|l|}{ (b) } \\
\hline 387.0 & 7.3842 & 7.3542 & 7.3220 & 7.3104 & 7.3029 & \multirow{5}{*}{$\begin{array}{l}(\mathrm{MTBF})_{2}=410, \mu_{2}=0.12 \\
(\mathrm{MTBF})_{3}=408, \mu_{3}=0.160 \\
(\mathrm{MTBF})_{4}=1131, \mu_{4}=0.009\end{array}$} \\
\hline 347.0 & 7.3890 & 7.3553 & 7.3230 & 7.3127 & 7.3114 & \\
\hline 307.0 & 7.3943 & 7.3580 & 7.3373 & 7.3281 & 7.3227 & \\
\hline 267.0 & 7.4031 & 7.3589 & 7.3434 & 7.3350 & 7.3294 & \\
\hline 227.0 & 7.4102 & 7.3599 & 7.3542 & 7.3353 & 7.3310 & \\
\hline
\end{tabular}

Table 3 Effect of failure and repair parameters of homogenizer on the availability of the system; Effect of failure and repair parameters homogenizer in reduced capacity

Table 4 Effect of failure and repair parameters of pasteurizer on the availability of the system; Effect of failure and repair parameters of pasteurizer in reduced capacity

\begin{tabular}{|c|c|c|c|c|c|c|}
\hline \multirow[t]{2}{*}{$\mathrm{MTBF}_{2}$} & \multicolumn{6}{|l|}{$\mu_{2}$} \\
\hline & 0.04 & 0.08 & 0.12 & 0.16 & 0.20 & Constant parameters \\
\hline \multicolumn{7}{|l|}{ (a) } \\
\hline 510.0 & 0.9461 & 0.9598 & 0.9619 & 0.9622 & 0.9628 & \multirow{5}{*}{$\begin{array}{l}(\mathrm{MTBF})_{1}=307, \mu_{1}=0.30 \\
(\mathrm{MTBF})_{3}=408, \mu_{3}=0.160 \\
(\mathrm{MTBF})_{4}=1131, \mu_{4}=0.009\end{array}$} \\
\hline 460.0 & 0.9422 & 0.9588 & 0.9607 & 0.9618 & 0.9622 & \\
\hline 410.0 & 0.9389 & 0.9552 & 0.9590 & 0.9600 & 0.9602 & \\
\hline 360.0 & 0.9207 & 0.9514 & 0.9573 & 0.9573 & 0.9584 & \\
\hline 310.0 & 0.9176 & 0.9491 & 0.9520 & 0.9537 & 0.9547 & \\
\hline \multicolumn{7}{|l|}{ (b) } \\
\hline 510.0 & 11.1640 & 8.7665 & 7.9615 & 7.5607 & 7.3114 & \multirow{5}{*}{$\begin{array}{l}(\mathrm{MTBF})_{1}=307, \mu_{1}=0.30 \\
(\mathrm{MTBF})_{3}=408, \mu_{3}=0.160 \\
(\mathrm{MTBF})_{4}=1131, \mu_{4}=0.009\end{array}$} \\
\hline 460.0 & 11.6990 & 9.0185 & 8.1162 & 7.6739 & 7.4026 & \\
\hline 410.0 & 12.3750 & 9.3683 & 8.3657 & 7.8635 & 7.5526 & \\
\hline 360.0 & 13.2140 & 9.7863 & 8.6217 & 8.0369 & 7.6941 & \\
\hline 310.0 & 14.3550 & 10.3970 & 9.0481 & 8.3840 & 7.9857 & \\
\hline
\end{tabular}

\begin{tabular}{|c|c|c|c|c|c|c|}
\hline \multirow{2}{*}{$\mathrm{MTBF}_{3}$} & \multicolumn{6}{|l|}{$\mu_{3}$} \\
\hline & 0.03 & 0.08 & 0.13 & 0.18 & 0.23 & Constant parameters \\
\hline \multicolumn{7}{|l|}{ (a) } \\
\hline 488.0 & 0.9095 & 0.9488 & 0.9584 & 0.9621 & 0.9645 & \multirow{5}{*}{$\begin{array}{l}(\mathrm{MTBF})_{1}=307, \mu_{1}=0.300 \\
(\mathrm{MTBF})_{2}=410, \mu_{2}=0.120 \\
(\mathrm{MTBF})_{4}=1131, \mu_{4}=0.009\end{array}$} \\
\hline 448.0 & 0.9054 & 0.9462 & 0.9558 & 0.9603 & 0.9652 & \\
\hline 408.0 & 0.9008 & 0.9416 & 0.9530 & 0.9589 & 0.9640 & \\
\hline 368.0 & 0.8897 & 0.9393 & 0.9520 & 0.9550 & 0.9613 & \\
\hline 328.0 & 0.8835 & 0.9324 & 0.9484 & 0.9527 & 0.9600 & \\
\hline \multicolumn{7}{|l|}{ (b) } \\
\hline 488.0 & 8.3301 & 8.0976 & 7.7566 & 7.5133 & 7.2941 & \multirow{5}{*}{$\begin{array}{l}(\mathrm{MTBF})_{1}=307, \mu_{1}=0.300 \\
(\mathrm{MTBF})_{2}=410, \mu_{2}=0.120 \\
(\mathrm{MTBF})_{4}=1131, \mu_{4}=0.009\end{array}$} \\
\hline 448.0 & 8.6734 & 8.2938 & 7.9400 & 7.6334 & 7.3052 & \\
\hline 408.0 & 9.0602 & 8.4226 & 8.1290 & 7.7528 & 7.4215 & \\
\hline 368.0 & 9.5885 & 8.7008 & 8.3279 & 8.0054 & 7.6533 & \\
\hline 328.0 & 10.0552 & 9.5911 & 9.0515 & 8.5219 & 8.0616 & \\
\hline
\end{tabular}


Table 5 Effect of failure and repair parameters of filler on the availability of system; Effect of failure and repair parameters of filler in reduced capacity

\begin{tabular}{|c|c|c|c|c|c|c|}
\hline \multirow[t]{2}{*}{$\mathrm{MTBF}_{4}$} & \multicolumn{6}{|l|}{$\mu_{4}$} \\
\hline & 0.005 & 0.007 & 0.009 & 0.011 & 0.013 & Constant parameters \\
\hline \multicolumn{7}{|l|}{ (a) } \\
\hline 1251.0 & 0.9006 & 0.9369 & 0.9495 & 0.9599 & 0.9639 & \multirow{6}{*}{$\begin{array}{l}(\mathrm{MTBF})_{1}=307, \mu_{1}=0.300 \\
(\mathrm{MTBF})_{2}=410, \mu_{2}=0.120 \\
(\mathrm{MTBF})_{3}=408, \mu_{3}=0.160\end{array}$} \\
\hline 1191.0 & 0.8957 & 0.9298 & 0.9499 & 0.9577 & 0.9637 & \\
\hline 1131.0 & 0.8901 & 0.9289 & 0.9461 & 0.9565 & 0.9628 & \\
\hline 1071.0 & 0.8865 & 0.9281 & 0.9457 & 0.9549 & 0.9613 & \\
\hline 1011.0 & 0.8770 & 0.9238 & 0.9425 & 0.9542 & 0.9599 & \\
\hline \multicolumn{6}{|l|}{ (b) } & \\
\hline 1251.0 & 15.9640 & 11.7980 & 9.4258 & 7.8785 & 6.8233 & \multirow{5}{*}{$\begin{array}{l}(\mathrm{MTBF})_{1}=307, \mu_{1}=0.300 \\
(\mathrm{MTBF})_{2}=410, \mu_{2}=0.120 \\
(\mathrm{MTBF})_{3}=408, \mu_{3}=0.160\end{array}$} \\
\hline 1191.0 & 16.7580 & 12.2950 & 9.7795 & 8.2325 & 7.1187 & \\
\hline 1131.0 & 17.5930 & 12.8900 & 10.2640 & 8.5893 & 7.4564 & \\
\hline 1071.0 & 18.5540 & 13.5580 & 10.8000 & 9.0537 & 7.8326 & \\
\hline 1011.0 & 19.6690 & 14.3810 & 11.4400 & 9.5416 & 8.2548 & \\
\hline
\end{tabular}
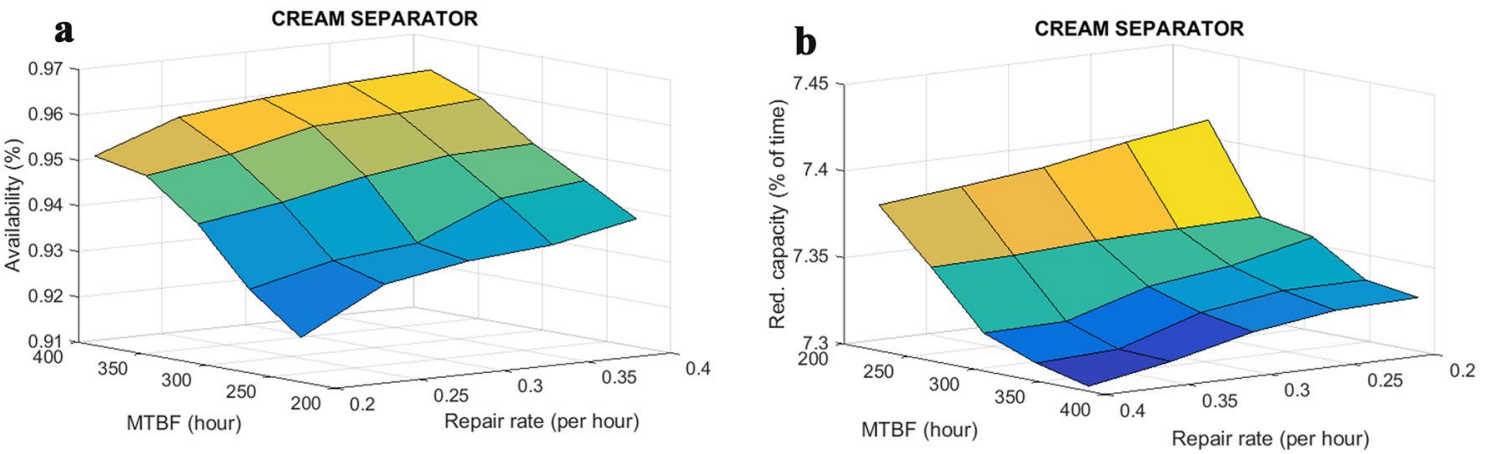

Fig. 6 Effect of failure and repair parameters of the separator on a availability; $\mathbf{b}$ reduced capacity
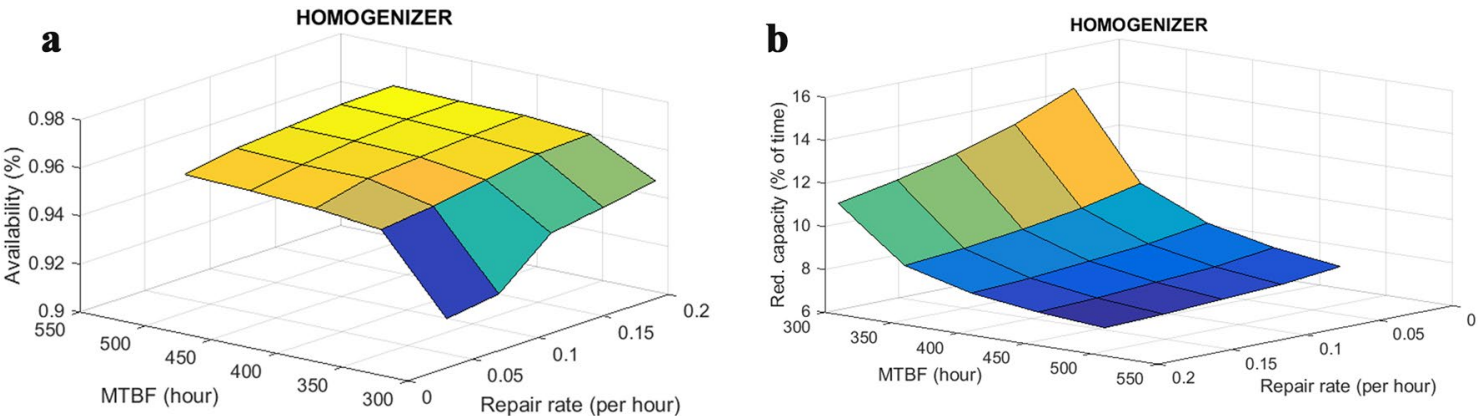

Fig. 7 Effect of failure and repair parameters of the homogenizer on a availability; $\mathbf{b}$ reduced capacity

working in a reduced capacity of $0.11 \%$ of the time for which plant is run. This is shown in Fig. $6 \mathrm{~b}$, and Table $2 \mathrm{~b}$.

Figure $7 \mathrm{a}$ and Table $3 a$ reveal that with variation in the failure and repair rates of the homogenizer, there is significant effect on the availability of the system. By decreasing MTBF of the homogenizer from 510 to 310 and decrease in repair rates of the same from 0.20 to 0.04 reduces the system's availability by $4.52 \%$. The identical variations in the failure and repair rates of the homogenizer have a higher effect on the system when the system is working in reduced capacity by $7.04 \%$ of the time for which plant is run. This is shown in Fig. 7b, and Table 3b.

Figure 8a and Table 4a depict that with variation in the failure and repair rates of the Pasteurizer, there is a significant effect on the availability of the system. Decreasing MTBF of the separator from 488 to 328 and decreasing the repair rate of the same from 0.23 to 0.03 reduces the system availability by $8.10 \%$. However, similar variations 

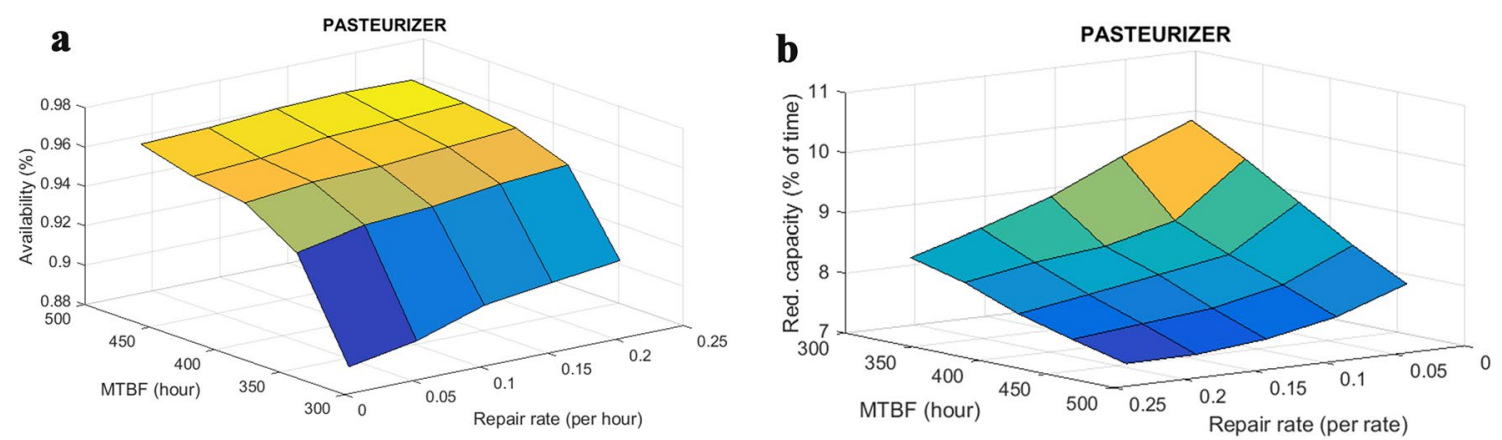

Fig. 8 Effect of failure and repair parameters of the pasteurizer on a availability; $\mathbf{b}$ reduced capacity

in the failure and repair rates of the separator have a relatively lower impact on the system's working in a reduced capacity $2.76 \%$ of the time for which plant is run. This is shown in Fig. 8b, and Table $4 \mathrm{~b}$.

Figure $9 a$ and Table 5a highlight that with the variation in failure and repair rates of the filler, there is a great impact on the availability of the system. An increase in the failure rate by decreasing MTBF of the separator from 1251 to 1011 and a decrease in repair rate of the same from 0.013 to 0.005 reduce system's availability up to $8.69 \%$. Moreover, similar variations in the failure and repair rates of the filler also have significant impact on the system when it is working in a reduced capacity of $12.85 \%$ of the time for which plant is run. This is shown in Fig. 9b, and Table 5 b.

\section{Profitability analysis}

As the availability of any functional unit is directly associated with the profitability in terms of revenue for its long run survival. We also investigated the effect of availability on the profitability of the plant under varying failure and repair parameters of various subsystems which can be useful for making strategies like spare parts, maintenance priorities and human resource. Gupta et al. [7] analysed profitability of a power plant using an equation for profit in steady state,

Profit, $P=\alpha \cdot A-\beta$;

where $a=$ Total revenue per unit up time, $\beta=$ the total repair cost, $A=$ Steady state availability (\%).

By considering, $a=5000$ and $\beta=500$.

So, Profit, $P=5000[A]-500$.

Profitability $(\%)=\frac{\text { Profit } \times 100}{\text { Total revenue }}$

The above formulae can be used to calculate the profit for corresponding availability. The variations in profit (\%) for maximum and minimum availability of a subsystem with respect to variations in failure and repair data are presented in Table 6. Based upon this we have made recommendation for the users which can further improve the performance of system.
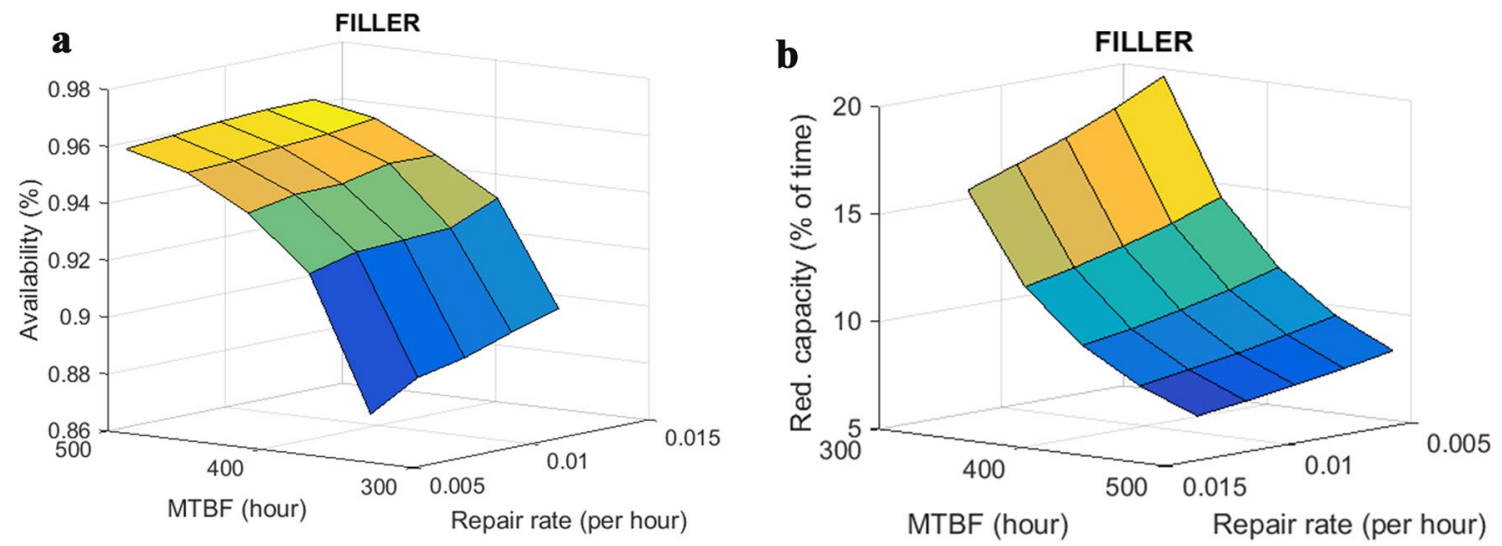

Fig. 9 Effect of failure and repair parameters of the filler on a availability; $\mathbf{b}$ reduced capacity 
Table 6 Decision support system (DSS)

\begin{tabular}{|c|c|c|c|c|}
\hline \multirow[t]{2}{*}{ Subsystem } & \multicolumn{3}{|c|}{ Observed effects (\%) on system } & \multirow{2}{*}{$\begin{array}{l}\text { Suggested } \\
\text { mainte- } \\
\text { nance } \\
\text { priority }\end{array}$} \\
\hline & Availability & $\begin{array}{l}\text { Reduced } \\
\text { capacity }\end{array}$ & Profit & \\
\hline Cream separator & 4.30 & 0.11 & 4.98 & IV \\
\hline Homogenizer & 4.52 & 7.04 & 5.24 & III \\
\hline Pasteurizer & 8.10 & 2.76 & 9.40 & II \\
\hline Filler & 8.69 & 12.85 & 10.10 & I \\
\hline
\end{tabular}

\section{Discussion}

In this study, the working of milk processing plant has been analysed using Petri Nets approach. The failure pattern is considered to follow Weibull distribution and repair rate exponential distribution. Whereas in relevant studies performance analysis carried out by Sachdeva et al. [14, 15], Gupta and Tewari [3], Kumar et al. [17, 18] and more recently Gupta et al. [11] used exponential failure as well as repair rates to formulate the mathematical performance model and evaluated system availability measures. For validation the approaches presented in mentioned studies have also been considered for modeling of the system under study. The graphical illustrations are intended to assist the practitioners to better understand the effect of failure and repair data on the system behavior. The movement of tokens in the Petri Nets model helps in understanding the interactions among subsystems and dynamic behavior of the system. Present results show that there is a significant scope in improving the working of such systems based on the results of such studies.

\section{Conclusions and recommendations}

The present work is a case study where we have considered a utility system which is being currently managed on the basis of intuitive decisions of the plant managers. Based upon detailed analysis, a Decision Support System (DSS) has been recommended to guide the practitioners which can be used likely to further improve its efficiency. It is presented in Table 6 . The significant findings of this work are the identification of the most critical of its subsystems that needs to be put on the top priority of maintenance strategies. It is concluded that the filler subsystem is the most critical of its subsystems. It is noticed that failure mainly occurs due to the failure of the pumps, Programmable Logic Control (PLC), and heating elements. In the existing literature failure pattern has not been given much importance and has been usually considered exponentially distributed. However most of the industrial systems are now Mechatronics in nature. Therefore, failure pattern should also be well defined. In the case of present study Weibull pattern is used.

Review of literature shows that the performance of Petri Nets in general superior to performance of Markov method of modeling; as it automatically simulates a large number of possible replication instances to choose the best. Markov technique essentially solves the set of governing differential equations for the supplied input data. It does not support time dependant failure patterns and more than one failure at a time, which may not be very appropriate. Use of PN formalism overcomes the certain limitations of Markov modeling. However, analytical techniques face certain inhibitions both from the management side as well as the engineering side. This restricts their use in certain types of practical problems as it has financial implications. It is further suggested that the process engineers should apply such techniques in real life practical situations so that a tradeoff gets established between financial investments and production volume of superior quality.

Acknowledgements Authors would like to place on record their appreciation of the facilities provided by officials of the VITA Milk Plant, Ambala, India. They would like to thank the license proprietor of software GRIF of Petri module for the use of their commercial software free of cost. The authors would like to extend their deep appreciation of the suggestions and comments of the learned referees that have enabled them to improve the quality of the manuscript. Authors would also extend heartiest thank to Dr. Chander Mohan (Retd. Prof. Indian Institute of Technology, Roorkee, India) for his valuable advice regarding the manuscript formatting.

\section{Compliance with ethical standards}

Conflict of interest On behalf of all authors, the corresponding author states that there is no conflict of interest.

\section{References}

1. Goel HD (2004) Integrating reliability, availability and maintainability in conceptual process design: an optimization approach. DUP Science. ISBN: 90-407-2502-0.

2. Narahari Y, Vishwanadham N (2015) Performance modeling of automated manufacturing systems. PHI learning pvt limited, Delhi

3. Gupta S, Tewari PC (2009) Simulation modeling and analysis of complex system of thermal power plant. J Ind Eng Manag 2(2):387-406

4. Okafor CE, Atikpakpa AA, Okonkwo UC (2016) Availability assessment of steam and gas turbine units of a thermal power station using Markovian approach. Arch Curr Res Int 6(4):1-17

5. Kumar A, Kumar V, Modgil V (2018) Performance optimization for ethanol manufacturing system of distillery plant using particle swarm optimization algorithm. Int J Intell Enterp 5(4):345-364

6. Dahiya O, Kumar A, Saini M (2019) Mathematical modeling and performance evaluation of a-pan crystallization system in a sugar industry. SN Appl Sci. https://doi.org/10.1007/s4245 2-019-0348-0 
7. Gupta N, Saini M, Kumar A (2020) Operational availability analysis of generators in steam turbine power plants. SN Appl Sci 2:779. https://doi.org/10.1007/s42452-020-2520-y

8. Marsan MA, Conte G, Balbo G (1984) A class of generalized stochastic petri nets for the performance evaluation of multiprocessor systems. ACM Trans on Comput Syst 2(2):93-122

9. Singh J, Garg S (2005) Availability analysis of core veneer manufacturing system in the plywood industry. In: International conference on reliability and safety engineering, Indian Institute of Technology, Kharagpur, pp 497-508

10. Sachdeva A, Kumar D, Kumar P (2008) Reliability analysis of the pulping system using Petri nets. Int J Qual Reliab Manag 25(8):860-877. https://doi.org/10.1108/02656710810898667

11. Sachdeva A, Kumar P, Kumar D (2009) Behavioral and performance analysis of feeding system using stochastic reward nets. Int J Adv Manuf Technol 45:156-169. https://doi.org/10.1007/ s00170-009-1960-8

12. Thangamani G (2012) Generalized stochastic Petri nets for reliability analysis of lube oil system with common-cause failures. Am J Comput Appl Math 2(4):152-158

13. Kumar N, Tewari PC, Sachdeva A (2019) Performance modeling and analysis of refrigeration system of a milk processing plant using Petri nets. Int J Perform Eng 15(7):1751-1759. https://doi. org/10.23940/ijpe.19.07.p1.17511759

14. Tavana M (2008) Dynamic process modeling using Petri nets with applications to nuclear power plant emergency management. Int J Simul Process Model 4(2):130-138

15. Ferreira C, Canhoto Neves L, Silva A, de Brito J (2018) Stochastic Petri net-based modeling of the durability of renderings. Autom Constr 87:96-105. https://doi.org/10.1016/j.autcon.2017.12.007

16. Dugan J, Trivedi K, Geist R and Nicola V (1984) Extended stochastic Petri nets: application and analysis. In: Proceedings of the performance '84, Paris, France. pp 507-519

17. Trivedi KS, Logothetis PDA (1995) From stochastic Petri nets to Markov regenerative stochastic petri nets. IEEE Xplore. https:// doi.org/10.1109/MASCOT.1995.378688

18. Jensen K (1981) Colored Petri nets and the invariant method. Theor Comput Sci 14:317-336

19. Feldmann K, Colombo AW (1998) Material flow and control sequence specification of flexible production systems using coloured Petri nets. Int J Adv Manuf Technol 14:760. https://doi. org/10.1007/BF01438228

20. Li H, Zheng H, Zhao H and Zheng Z (2018) Research on the availability analysis method of navigation satellite based on Petri nets. In: 2018 Proceedings of China satellite navigation conference (CSNC). pp. 127-136
21. Donatelli S, Haddad S (2020) Expressiveness and conciseness of timed automata for the verification of stochastic models. In: Leporati A, Martín-Vide C, Shapira D, Zandron C (eds) Language and automata theory and applications. LATA 2020., vol 12038. Lecture Notes in Computer Science. Springer, Cham

22. Desrochers AA, Al-Jaar RY (1995) Applications of Petri nets in manufacturing systems. IEEE Press, New York

23. Zhu D, Tan H, Yao S (2018) Petri nets-based method to elicit component-interaction related safety requirements in safetycritical systems. Comput Electr Eng 71:162-172

24. Brauer W, Reisig W and Rozrnberg G (1987) Advances in PN ,Part I Petri nets: central models and their properties, In: Proceedings of advanced course, Bad Honnef,Germany. Lecture notes in computer science, vol.254. Springer-Verlag, Berlin.

25. Brauer W, Reisig W and Rozrnberg G (1987) Advances in PN, Part II Petri nets: applications and relationships to other models of concurrency. In: Proceedings of advanced course, Bad Honnef, Germany. Lecture notes in computer science, vol.255. SpringerVerlag, Berlin

26. Kurkovsky S, Loganantharaj R (2005) Extension of Petri nets for representing and reasoning with tasks with imprecise durations. Appl Intell 23(2):97-108. https://doi.org/10.1007/s1048 9-005-3415-8

27. Aggarwal AK, Sanjeev K, Vikram S (2016) Reliability and availability analysis of the serial processes in skim milk powder system of a dairy plant: a case study. Int J Ind Syst Eng 22(1):36-62

28. DekkerR GW (1995) Availability assessment methods and their application in Practice. Microelectron Reliab 35(9-10):1257-1274

29. Dhillon BS, Yang N (1997) Comparisons of block diagram and Markov method system reliability and mean time to failure results for constant and non-constant unit failure rates. Microelectron Reliab 37(3):505-509

30. Kuchárik M, Balogh Z (2019) Modeling of uncertainty with Petri nets. In: Nguyen N, Gaol F, Hong TP, Trawiński B (eds) Intelligent information and database systems, ACIIDS 2019. Lecture notes in computer science, vol 11431. Springer, Cham.

31. Molloy MK (1982) Performance analysis using stochastic Petri Nets. IEEE Trans Comput 31(9):913-917

Publisher's Note Springer Nature remains neutral with regard to jurisdictional claims in published maps and institutional affiliations. 